\title{
DOS PROCESOS DINÁSTICOS PARALELOS EN LA DÉCADA DE 1520 CARLOS VY SU HERMANO FERNANDO I
}

\author{
por \\ JUAN ANTONIO VILAR SÁNCHEZ \\ Universidad Católica de Nimega
}

RESUMEN: Hasta 1520 Carlos babia cumplimentado la primera etapa en su proceso dinástico, La obtención de casi toda su berencia patrimonial. La segunda etapa, la conservación de tan vasto imperio, se mostró barto dificil y por ello, desde 1522, Carlos fue cediendo partes de su patrimonio y de sus derechos a su bermano Fernando, que a su sombra, fue creando su propio patrimonio dinástico, la Alta Alemania-Austria, las coronas bereditarias de Bobemia y Hungria y finalmente los derechos sobre el Imperio. La tercera etapa del proceso dinástico, la fijación de un beredero en que dejar asegurado todo el proceso, estaba ya también muy clara desde 1525. Carlos babía decidido que necesitaba de dos berederos, un bijo propio para sus tierras patrimoniales, y su bermano Fernando para sus derechos sobre el Imperio. La consecución de ambos fines, sin fijar cual era el más importante de los dos, siguió un único camino con dos metas diferenter. Fundamental en erta tercera etapa dinástica fue el proceso de preparación de la boda imperial, su realización en Sevilla, el embarazo en Granada, $y$ el nacimiento en 1527 del beredero en Valladolid. La meta que parecia ser la principal a lo largo de todo ese proceso, la unción y coronación imperial en Roma y la elección de Fernando camo rey de Romanos, fue quedando postergada por los acontecimientos y solo se alcanzó en 1530 y 1531 , cerrando la tercera etapa en la carrera dinástica de Carlos $V$.

PAlABRAS Clave: Imperio. Dinastía. Carlos V. Fernando I.

ABSTRACT: Up to 1520, Charles bad fulfilled the first stage of bis dynastic process: the attainment of nearly all bis patrimonial beritage. The second stage, the preservation of this great empire, proved a difficult one, so from 1522 the emperor transferred some parts of bis oun patrimony and rights to bis brotber Ferdinand. The latter created bis own dynastic patrimony, made up of a part of bis German territories,

Hiphonic, LX/3, núm. 206 (2000) 835-852 
Austria, the bereditary crowns of Bobemia and Hungary and finally the rights over the empire. The tbird stage, the establisbment of an beir to secure the dynastic process, was initiated as early as 1525. Charles in fact decided be needed two beirs: a son of his oun for bis patrimonial possessions, and bis brotber Ferdinand for the empire. The attainment of botb aims, without establisbing which of them was the main one, followed a single path, but with two different aims. Fundamental in this third process were the arrangements for the imperial wedding, its celebration in Seville in 1526, the pregnancy of Isabel de Portugal in Granada in the same year, and the birth of an beir in Valladolid in 1527. The main gaal in this process, the imperial coronation in Rome and the election of Ferdinand as king of Romanr, were postponed due to the bistorical events and were fulfilled in 1530 and 1531, concluding the third stage in the dynastic course of the emperor Cbarles $V$.

KEY WORDS: Empire. Dinaty. Charles V. Ferdinad I.

Hacia 1520 Carlos V había alcanzado ya gran parte de los objetivos que se había señalado en su carrera por heredar los títulos y posesiones de sus antepasados$^{1}$. La labor no había sido nada fácil, ya que a excepción de en Borgoña, donde no había tenido émulo, tanto en Castilla como en Aragón la sombra de su hermano Fernando había puesto en tela de juicio su consecución. Por el Imperio la lucha había sido aún más dura, sin cuartel, y contra un enemigo rico y poderoso, Francisco I de Francia. Hacia 1520, el emperador comenzaba a aliviarse del estado de ansiedad perenne en que había vivido desde 1515, en lucha continua y en todos los frentes por alcanzar su herencia, defendiendo lo que él consideraba suyo por derecho, tanto de familiares como de enemigos. Hacia 1520, Carlos había conseguido ya emular a todos sus antepasados, e incluso superarlos ampliamente en el valor de sus posesiones y derechos, reuniendo en una sola persona las herencias de los duques de Borgoña, de los archiduques de Austria, de los reyes de Castilla y Aragón, e incluso los derechos imperiales. Este ingente conglomerado multiétnico y plurilingüe se convirtió rápidamente en una pesada carga para el joven emperador que se veía ahora ante el ineludible deber de defender ese patrimonio dinástico heredado de sus antepasados 0 aumentado por él, debiendo estar dispuesto a cualquier confrontación en defensa de sus derechos, sin permitir que ni el más mínimo ápice del patrimonio fuera disminuido.

Si el primer objetivo, el de la creación del patrimonio dinástico familiar, se había alcanzado, el segundo, el de la conservación integra de todos esos territorios y derechos, supondría desde ese momento y hasta su abdicación final, casi cuatro décadas ininterrumpidas de guerras y enfrentamientos por su defensa,

1 Aún en 1524 uniría Carlos Frisia, en 1528 Utrecht y Overijssel, en 1532 Jever-Kniphausen, en 1536 Drente y Groningen, en 1543 Gïeldres y Zutphen. También aseguraría sus derechos sobre el Milanesado y aumentaría sus posesiones en el norte de Africa, en América y en las islas de las especias, allende la mar oceana.

Hispania, LX/3, núm. 206 (2000) 835-852 
concluidas para él con la cesión del problema a sus herederos. Ya en 1522, la gran presión que sufría Carlos y la imposibilidad de estar en todas partes a la vez en un conglomerado separado geográficamente en al menos cuatro grandes bloques, los territorios ibéricos, los italianos, los de la Baja Alemania y los de la Alta Alemania-Austria, le llevó a comprender que quizás había ido demasiado lejos en su política de unión de tan ingente herencia. Uno de los bloques territoriales, el de la Alta Alemania-Austria, casi al completo, fue cedido definitivamente a su hermano Fernando en Bruselas en 1522. De esa forma, como príncipe del Imperio, podía actuar Fernando con más prestancia como su lugarteniente, en las ausencias de Carlos, al frente del regimiento imperial. Fernando se reveló además como la figura idónea para el cargo, tolerante, comprensivo y sobre todo consciente de que ese área geográfica, tan ajena a su calidad de nativo español, podía ser el único lugar donde alcanzar su objetivo primario de crear un nuevo patrimonio dinástico propio que trasmitir a sus herederos. Su labor como sustituto de su hermano fue muy buena, y prueba de ello es que Carlos no tuvo necesidad de presentarse en esos territorios en toda la década de los años veinte, ni tan siquiera en momentos tan graves como la muerte de Luis II de Hungría y el acoso turco al frente oriental del Imperio.

Conseguidos el primer y segundo objetivos en la carrera dinástica, i.e. la creación y la consolidación de tan vasto imperio, el tercer objetivo era la fijación de un heredero, o mejor aún de una cadena de herederos, que aseguraran en el futuro, ante cualquier eventualidad, la posesión de los derechos a la famiLia. Herederos indirectos existían ya, entre otros el hermano del emperador, Fernando, que demostraba además muy buenas cualidades para ello. Pero la herencia se comprendía más en los hijos, en los herederos directos, y Carlos a los veinticinco años se encontraba en su quinto compromiso matrimonial fir$\mathrm{me}^{2}$, esta vez con su prima hermana María, hija de Enrique VIII y Catalina de Aragón, pero sin visas de que la boda madurara por el momento y mucho menos de que esa unión produjera en corto plazo el ansiado heredero.

Como no todos los derechos y bienes poseídos por Carlos tenían un carácter hereditario, (el Imperio por ejemplo era electivo), y debido a la inexistencia de un heredero directo y al tiempo que tardaría aún, si lo hubiera, en alcanzar su mayoría de edad, Carlos decidió asegurar esos derechos, no hereditarios, en su hermano Fernando. El proceso que se seguiría para intentar «asegurar» en par-

2 TYLeR, Royall: El emperador Carlas V, Barcelona 1972, p. 35; DE ForondA Y AGUILERA, Manuel: Viajer y estancias del emperador Carlas V, Madrid 1914, pp. 671-672. El 20 de agosto de 1501, Carlos fue prometido a Claudia, hija de Luis XII de Francia, compromiso deshecho cuatro años más tarde para casar con Francisco I. El 2 de diciembre de 1507, se le prometió a María, hija de Enrique VII de Inglaterta, con quien casatía más tarde Luis XII. El 24 de matzo de 1515 se comprometió con Renata de Francia, segunda hija de Luis XII, de cinco años de edad, trato también deshecho. Por el tratado de Noyon, en agosto de 1516, se prometió a Luisa, hija de Francisco I, que sólo tenía un año y que moriría al año siguiente. En 1521 se comprometió con María de Inglaterra, de cinco años de edad. 
te la futura elección imperial en la persona de Fernando era su elección previa, en vida de Carlos, como rey de Romanos. Esa elección era imposible sin que el emperador hubiera sido ungido y coronado por el papa.

Dos objetivos divergentes se convirtieron en fundamentales para las políticas dinásticas del emperador en sus dos diferentes vertientes, la de los territorios propios hereditarios y la de los derechos imperiales y electivos. Estos dos objetivos eran su matrimonio, por el que podría acceder a un heredero propio, y su coronación papal, tras la cual podría hacer elegir a su hermano como rey de Romanos. Ambos objetivos, íntimamente unidos entre sí, aunque en una primera observación no lo parezca, se convirtieron para Carlos en fundamentales desde 1525, y casi todas sus acciones, desde esa época, fueron dirigidas a su consecución. En esa duplicidad de objetivos dinásticos, alcanzar uno de ellos sólo era factible teniendo en cuenta el otro. Por ello el primero de los objetivos, el matrimonio del emperador, llevó siempre como condición previa y necesaria, en vistas a alcanzar el segundo objetivo, la fijación de una fuerte dote, que le permitiera, ante la debilidad de sus finanzas, el ansiado viaje con su séquito a Italia y los gastos de la coronación imperial. Esa idea de la coronación imperial, que por cierto su antecesor Maximiliano I no había cumplimentado, existía ya desde poco después de su elección como emperador y la vemos claramente en una carta de su consejero y maestro Adriano de Utrecht tras ser elegido papa, escrita aún en la península antes de partir hacia Roma para su entronización: «Esperamos que, después de que vuestra majestad haya compuesto y arreglado sus asuntos de por ahí, dentro de pocos años, venga a vernos a Roma, para tomar la corona imperial .... ${ }^{3}$

No nos es fácil descubrir a través de la correspondencia imperial cual de los dos objetivos, la boda y obtención de un heredero directo, o la coronación imperial, era el más importante para el emperador, aunque nos parece entrever que el primero pudiera haber sido sólo un medio para alcanzar el segundo.

Hasta 1525 , y a pesar de la buena dote ofrecida por diversas candidatas, Carlos había hecho oídos sordos a sus solicitudes, incluso a la de Juan III de Portugal, que pretendía realizar una boda doble entre ambas dinastías. Según sus planes, Juan casaría con la infanta Catalina, la hermana menor del emperador, y Carlos con la infanta Isabel, hermana del rey portugués. El compromiso matrimonial estipulado con su prima hermana María y la necesidad de mantener la amistad con su tío Enrique, tenían aún a principios de 1525 , un alto valor para el emperador. Por ello en ese año sólo se pudo llevar a efecto la primera de las dos bodas planeadas, la de Catalina y Juan III, quedando la segunda en suspenso. Desde febrero de 1525, y ante los cambios políticos acaecidos

3 LANZ, Kari: Correspondenz des Kaisers Karl V. Aus dem königliscben Arcbiv und der Bibliothiquue de Bourgogne zu Brïssel, vol. 1, Frankfurt/Main 1966, p. 63. Carta de Adriano IV al emperador, 27 de julio de 1522: «Nous esperons que, apres avoir bien compose et addrecie vostre majeste ses affaires par deça, en dedans peu d'annees, elle nous viendra veoir en Rome, pour prendre la choronne imperiale ...." 
en Pavía con la derrota y encarcelamiento de Francisco 1, los objetivos dinásticos pasaron a ocupar ya sin paliativos un lugar primordial en la política del césar, aunque llevaran implícitos un posible enfriamiento de las relaciones con el rey inglés. La amistad y colaboración con Enrique VIII dejaba de tener una importancia vital ${ }^{4}$. Además, el posible matrimonio de Carlos con la infanta portuguesa era muy bien visto e incluso deseado en Castilla, cuyas cortes apoyaron desde el primer momento la idea. Por ello el problema inglés fue solventado, no de muy buena forma, por medio de una embajada harto exigente $e$ imposible de aceptar por Enrique VIJI, realizada por el comendador Peñalosa ante la corte inglesa ${ }^{5}$. Tras ella, Carlos se vio exonerado del cumplimiento del compromiso dado y con libertad para negociar con el rey portugués.

En la primavera de 1525 , el emperador decidió retomar las negociaciones directas acerca de la posible boda portuguesa, enviando para ello a la corte lusitana a su consejero y sumiller de corps, señor de La Chaulx. El 17 de octubre de 1525 en Torresnovas, tras largos meses de negociaciones, quedaron definitivamente fijadas las capitulaciones matrimoniales entre Carlos e Isabel. Uno de los puntos más importantes del acuerdo, para Carlos, fue el que estipulaba la dote en 900.000 doblas de oro castellanas de 365 maravedíes. Cantidad que no sería pagada en su totalidad ya que de ella se habrían de descontar 23.076 doblas que ya había usado Isabel de la herencia de su madre María, más 165.732 que el emperador adeudaba aún a Juan III de la dote de la reina Catalina, y otras 51.369 que el césar debía desde la guerra de las comunidades a Manuel de Portugal por la ayuda prestada. Restaba aún un total de 682.898 doblas, con las que Carlos podría costearse sin problemas la coronación imperial y otros gastos anexos. Se estipuló que de esa cantidad restante, 250.000 doblas se pagaran en Medina del Campo u otra ciudad castellana en diciembre de 1525, 100.000 en dos mitades, se colocarían en Flandes en dos plazos, San Martín y la Pascua, y otras $\mathbf{1 0 0 . 0 0 0}$ serían pagadas en Italia o en Castilla a finales de marzo de 1526. Sobre el resto de 182.898 doblas, a pagar en los dos siguientes años, se descontaría el valor de las joyas que Isabel sacara de Portugal. Un día más tarde, el 18 de octubre de 1525 , eran juradas las capitulaciones por el rey Juan III de Portugal y el 24 de octubre del mismo año, lo hacía en Toledo Car$\operatorname{los} V^{6}$.

4 Ochoa BRUN, Miguel Angel: Historia de la diplomacia española. La diplomacia de Carlos V, vol. 5, Madtid 1999: Biblioteca Diplomática Española, Sección Estudios 6, p. 347, 1699: Enrique VIII se sentía herido por el cambio de actitud ocurrido en Carlos desde la batalla de Pavía, ya que si antes le escribia siempre de su mano, firmando como utuus filius et cognatus», que es «tu hijo y pariente", desde ese momento sólo le escribía de mano ajena y firmaba sólo «Carlos*.

5 Carlos envió a Ruy Díaz de Peñalosa a solicitar de Enrique VIII la entrega al césar de la princesa María, de nueve años, y su consiguiente traslado a España, a lo que se negó en rotundo el monarca inglés. Carlos consideró desde ese momento el compromiso matrimonial con su prima como deshecho.

6 Fernández Álvarez, Manuel: Corpus documental de Carlos V, vol. 1, Salamanca 1973, pp. 100-115: Capitulaciones matrimoniales de Carlos e Isabel, Toledo 24 de octubre de 1525. 
Antes de que se alcanzara el acuerdo, aún en medio de las negociaciones, en junio de 1525, Carlos escribió a su hermano Fernando informándole de la importancia para ambos de esa dote, que el emperador estipulaba en una cantidad cercana al millón de ducados de oro, ya que con ella podría costearse el viaje a Roma para la coronación, pudiendo dejar, tras la boda, los negocios de Castilla en manos de su mujer como regente, apoyada por un buen consejo ${ }^{7}$. Parecía pues como si la boda sólo fuera el camino y medio para la anhelada coronación, que día a día se iba revelando como el objetivo fundamental de la política del césar.

Para esa coronación, además de los importantes fondos económicos obtenidos de la dote, Carlos decidió usar también de la prisión de Francisco I. Por ello estipuló en el punto nueve de la Concordia de Madrid, del 14 de enero de 1526 , aceptada por Francisco I como condición para recobrar la libertad, «que el primer viaje que el emperador querrá pasar a Italia, el dicho señor Cristianísimo, dentro de dos meses después que de ello fuere requerido, enviará a su costa y expensa, al puerto o lugar que será para ello señalado y donde el dicho señor emperador querrá embarcar para el dicho viaje a Italia, todas las naos, galeras, galeones y otros vasos cualesquier de su armada de mar, es a saber, doce galeras ... más cuatro galeones, todas las cuales bien artilladas y fornidas solamente de artillería y munición para ello necesario y marineros y oficiales necesarios ... sin poner en ellas alguna gente de guerra ... y esto por el término y espacio de diez meses, que contarán desde el mismo día que el dicho señor emperador embarcará y se hará a la vela para dicho viaje»"

No nos queda ya duda, a comienzos de 1526 su objetivo prioritario era la coronación en Roma. Todos sus esfuerzos se dirigían a ello, y a ello supeditaba el resto de su política internacional. $Y$ así lo vemos nuevamente en febrero de 1526, en el momento de la liberación de Francisco I. El emperador, antes de partir hacia Sevilla para su boda, ordenaba desde Toledo a Lope de Soria, la reunión de la flota propia y aliada en Cataluña. Las carracas y galeras de Génova debían de ser enviadas con celeridad al puerto de Xalo (Salou) para asegurar su paso a Italia. Las galeras de Sicilia, las de Galeazo Gono, las de los reinos de Aragón y Nápoles, debían de reunirse en Barcelona, "para llevar y acompañar nuestra persona, de manera que en todo caso sean en el puerto de Xalo al fin del dicho mes de abril» de 15269. La firma de la Concordia de Madrid, la creencia aún en la palabra dada por Francisco I, hacían creer al emperador que «su pasada a Italia sería fácil»10.

7 FERNÁNDEZ Álvarez, Manuel: (1973), p. 117, 40.

8 MexiA, Pedro: Historia del emperador Carlos V, Madrid 1945, p. 418.

9 Fernández Álvarez, Manuel (1973), pp. 115-117: Carta de Carlos V a Lope de Soria, Toledo, 7 de febrero de 1526.

10 De Sandovat, Prudencio: Historia de la vida y bechos del emperador Carlos V, vol. 2, Madrid 1955 , p. 137.

Hispania, LX/3, núm. 206 (2000) 835-852 
Antes de ello, Carlos tenía que cumplir con el trámite de casarse con una mujer a la que no conocía personalmente, sí por medio de las informaciones de su hermana menor Catalina, agente que favorecía ante su hermano la boda con Isabel. En las capitulaciones matrimoniales había quedado estipulado que ambos casarían por poderes en cuanto llegara la dispensa papal para la boda, y así se hizo a principios de noviembre de 1525 , aunque sin valor, ya que la dispensa papal no era completa y hubo que pedir una nueva. Por segunda vez se volvieron a casar por poderes el 20 de enero de 1526 , cuando llegó la segunda dispensa papal. Antes de esa segunda boda, el césar, que a la sazón se encontraba en Toledo, había enviado ya una delegación encabezada por Hernando de Aragón, duque de Calabria; Alonso de Fonseca, arzobispo de Toledo; y Alvaro de Zúñiga, duque de Béjar, hacia la frontera portuguesa para recibir a la novia y acompañarla a Sevilla. El emperador no podía hacerlo personalmente al estar ocupado en las negociaciones con el rey francés, aún prisionero suyo. El 7 de febrero de 1526, era entregada la emperatriz en la raya, cerca de Elvas, a los enviados españoles que, ante la sucesión de acontecimientos que se estaban desarrollando, llevaban la consigna de contener la marcha. Una semana completa se detuvieron en Badajoz, donde Isabel fue agasajada con bellas fiestas y regocijos, organizados por los vecinos y el regimiento de la ciudad. El sábado 3 de marzo la emperatriz era recibida cerca de Sevilla, por el duque de Arcos, alcalde mayor de Sevilla, el regimiento y caballeros de la ciudad ${ }^{11}$. A lomos de un caballo ricamente ataviado, entró en Sevilla por la puerta de la Macarena, desde donde continuó bajo palio de brocado hasta la catedral, siendo a continuación acompañada hasta el Alcázar Real, donde fue muy bien aposentada con sus damas ${ }^{12}$, según Gonzalo Fernández de Oviedo en la llamada torre del Aceite, que estaba junto a la puerta de la iglesia ${ }^{13}$.

Carlos, una vez finalizada su misión ante Francisco 1, dirigió el 21 de febrero sus pasos hacia Sevilla, a donde llegó el 10 de marzo de $1526^{14}$. El recibimiento dado al emperador y a su séquito, entre el que destacaba el cardenal Salviatis, nuncio papal, que traía la dispensa para la boda, no fue inferior al recibido por la emperatriz. Dos leguas antes de la ciudad era esperado por el alcalde mayor, duque de Arcos. Al llegar a la puerta de la ciudad le esperaba el arzobispo, y allí juró respetar todos los privilegios, usos y costumbres de Sevi-

It Para conocer con todo detalle el traslado de Isabel desde Portugal hasta la "raya", su entrega a los enviados de Carlos y despedida de sus hermanos, las fieseas habidas en Badajoz, las ordenes imperiales de entrecener al cortejo mientras él acababa de solucionar el problema francés, el deambular por Extremadura del cortejo de la emperatriz durante veinticuatro días, en un trayecto que no hubiera requerido más de seis jornadas, y el recibimiento en Sevilla, merece la pena leer el trabajo magistral de CARriazo y ANTIOQUía, Juan de Mata: «La boda del emperador. Notas para una historia del amor en el Alcázar de Sevilla» en Arcbivo Hispalense (Sevilla) 30 (1959), pp 2-108/60-86.

12 De Santra CruZ, Alonso: Cnónica del emperador Carlos V, vol. 2, Madrid 1920, pp. 227-229.

13 Carriazo y Antioquía, Juan de Mata (1959), p. 86.

14 GACHARD, L.P.: Voyages des satuverains des Pays-Bas, vol. 2, Bruselas 1874, p. 27. 
1la. A caballo, bajo palio y acompañado por ellos, a través de los arcos de triunfo levantados por las corporaciones de la ciudad, llegó, ya oscurecido, a la Catedral a dar gracias, y dos horas después de entrada la noche, acompañado de un gran número de servidores con hachas, al Alcázar, donde le esperaba la emperatriz" ${ }^{15}$. «La emperatriz se hincó de rodillas e porfió mucho por le besar la mano. El emperador se abajó mucho a la levantar, abrazándola, e la besó e la tomó por la mano e se entraron en otra cámara e se sentaron. E después de un cuarto de hora estuvieron allí, con muchos grandes, el emperador se pasó a su aposento, e se quitó la ropa de camino que traía, e se vistió muy ricamente, e tornó a donde la emperatriz estaba ...»16

Esa misma noche, y delante de testigos, el cardenal Salviatis dispensó a la pareja para casarse por ser primos hermanos y por hacerlo en Cuaresma, y los desposó por palabras de presente en la "quadra grande llamada de media naranjan del alcázar sevillano. El señor de La Chaulx inició un baile, tras el cual cenaron todos juntos y se retiraron los novios cada cual a sus apartamentos. Poco después de la media noche, hacia las dos de la madrugada «queriéndolo el rey por su honestidad y religión", fue aderezado un altar en una cámara del Alcázar y el arzobispo de Toledo dijo una misa rezada «basse messe» y los veló. Fueron sus padrinos el duque de Calabria, Hernando de Aragón y la camarera mayor de la emperatriz, Angela de Fabres y Centelles, condesa de Odenura y Faro. «Acabada la misa, se pasó el emperador a su aposento que serían ya las dos después de media noche. En tanto que el emperador estaba en su cámara, se acostó la emperatriz e desque fue acostada, pasó el emperador a consumar el matrimonio, como católico príncipe» ${ }^{17}$.

La alegría en el reino era grande y «la emperatriz paresçió a todos una de las más hermosas princesas que a avido en el mundo, como ella lo hera en verdad, e dotada de singular hermosura e bondad de ánimo" ${ }^{18}$. Una de las descripciones más interesantes de lo acaecido es el testimonio de un testigo de la boda, Guillermo des Barres, enviado por la archiduquesa Margarita, tía del emperador y gobernadora general de los Países Bajos, con el fin de informar al emperador y de llevar un regalo nupcial a Isabel. Guillermo narra los hechos de forma detallada para su dueña y dice: «Yo estuve presente la primera vez que el emperador se acercó a Isabel, en la cena y en los desposorios, y nunca había visto dos recién casados más contentos el uno con el otro que ellos, parecía como si se hubieran criado juntos ... si ya os han contado algo de sus bellezas, virtudes y buenas maneras, estoy seguro de que si la viérais encontraríais muchas más, sobre todo el placer de ver la felicidad que tienen de poder estar el

15 De Sandoval, Prudencio (1955), pp. 163-165; De Santa Cruz, Alonso (1920), p. 230; MeXiA, Pedro (1945), p. 425; GACHARD, L.P. (1874), p. 75.

16 Carriazo y Antioguí, Juan de Mata (1959), pp. 92-93: Tomado de Gonzalo Fennández de Oviedo.

17 Carriazo y Antroquía, Juan de Mata (1959), p. 93.

18 De Sandoval, Prudencio (1955), p. 165; MEXIA, Pedro (1945), p. 425. 
uno con el otro. Ruego a Dios que les conceda la gracia de vivir juntos largo tiempo. No os cuento nada de las celebraciones de las nupcias, ya que solo se han celebrado bailes, además su Majestad estaba constantemente ocupado en hacer de buen marido y solo se preocupaba de los portugueses que habían acompañado a la emperatriz, no ha tenido tiempo para negociar ningunos otros asuntos. No quiero olvidar de deciros que el día de los esponsales la Emperatriz llevaba vuestra joya (el regalo que había traído él) colgada del cuello y que la tenía en gran estimas ${ }^{19}$. Carlos se vio sorprendido por la belleza de su mujer y sintió un gran amor por ella, amor que lo mantenía ocupado lejos del trabajo, convirtiendo cada día en domingo. Casi a diario se quedaban «en la cama hasta las diez y las once de la mañana». El marqués de Vilareal contaba en carta al secretario Antonio Carneiro que «la Emperatriz duerme cada noche con su marido en brazos, y están muy enamorados y muy contentos». Las noticias y detalles de esta felicidad se filtraban al exterior a través de los jóvenes ayudantes flamencos del emperador, y algunas particularidades de ello se hicieron públicas para el placer y felicidad del pueblo sevillano, que disfrutaba con la felicidad de sus teyes ${ }^{20}$.

Las celebraciones, como ya había dicho Des Barres, no se prolongaron demasiado tiempo, ya que dos noticias vinieron a empañarlas. La primera y más importante fue la muerte de Isabel, la hermana del emperador, en el exilio, en el castillo de Swinarde, cerca de Gante. Aquí vuelve a demostrar Carlos que anteponía su política dinástica a sus propios sentimientos. Los cronistas se equivocan al decir que la noticia llegó al emperador a los cuatro o cinco días de la boda, "por lo qual uvo de traher luto çiertos días" y las fiestas fueron pospuestas ${ }^{21}$. La realidad fue completamente diferente. La noticia de la muerte de su hermana Isabel se la trajo el enviado de Margarita, Guillermo des Barres, y se la comunicó al emperador en el pueblo de Almadén de la Plata, el día 8 de marzo, dos días antes de su entrada triunfal en Sevilla ${ }^{22}$. La noticia estremeció al emperador, pero para evitar posponer la boda y su planeado y deseado viaje a Italia, mandó al mensajero que no dijera a nadie nada de ello hasta después de los esponsales, lo que este hizo.

La segunda noticia que turbó la paz de la boda fue el ajusticiamiento del obispo de Zamora, uno de los cabecillas de las comunidades castellanas, que, intentando escapar de la prisión de Simancas donde estaba encarcelado, asesinó

\footnotetext{
19 Algemeen Rijksarchief te Brussel. Bruselas:ARAB. Audiëntie, $n^{\circ}$ 35: Carta de Guillermo des Barres a Margatita de Austria, del 22 de marzo de 1526, Sevilla.

20 Carriazo Y ANTIOQuia, Juan de Mata (1959), pp. 103-104.

21 GACHARD,L.P. (1874), p. 75.

22 ARAB. Audiëntie, $n^{\circ}$ 35: Carta de Guillermo des Barres a Margarita de Austria, Sevilla, 22 de Marzo de 1526: "Je trouvay l'Empereur en ung village à dix lyeues de ceste ville le 8. de ce mois (mars). J'euz audience a sa Maiesté le lendemain avant qu'il partit de son lit, je luy declaray la pluspart de ma charge, il fut tresayse scavoir de voz nouvelles du trespas de la Reyne de Dennnemarck, ce qu'il fit tayre jusques aprés ses noepces».
} 
a su vigilante, el alcaide Mendo de Nogueroa. La noticia del asesinato del alcaide le llegó al emperador también en el camino a Sevilla el día 1 de marzo en la ciudad de Trujillo. Para hacer justicia, envió el emperador a Simancas al alcalde de corte, el licenciado Ronquillo, que, siguiendo las instrucciones de su señor, dio garrote vil al arzobispo y después lo mandó ahorcar de las almenas del castillo ${ }^{23}$. Carlos era consciente de lo que sus actos suponían, «no es liçito a los rreyes ni potençias seglares tocar ni castigar a los ungidos e consagrados a Dios» anotaba su cronista Mexía, la consecuencia era la excomunión directa. El día 11 de marzo, el día de la boda, llegó la noticia a Sevilla del ajusticiamiento del obispo ${ }^{24}$. Junto con el emperador eran excomulgados el licenciado Ronquillo, como autor material, y el secretario Francisco de los Cobos, como partícipe en los hechos. Desde ese momento el emperador se abstuvo de «oyr misa, ni los ofiçios divinos" y envió directamente emisarios a Roma para solicitar la absolución papal, que llegó el último día del mes de abril «e no con poca dificultad", absolución que solo era válida para el emperador, los otros dos, Cobos y Ronquillo, siguieron excomulgados ${ }^{25}$.

A mediados de marzo el emperador volvió a fijar nuevamente sus planes para el futuro próximo y ordenó los preparativos. Deseaba abandonar Sevilla a finales de abril para ir a Granada, donde apenas si permanecería unos días, y de ahí continuar hacia Valencia, donde pensaba reunir las cortes de Aragón, Cataluña y Valencia, y después a Barcelona, embarcando en su puerto en septiembre rumbo a Roma. El viaje a Italia y su coronación por el papa seguían siendo, a pesar de todo, el objetivo principal de Carlos, que reiteraba a Margarita no estar dispuesto a retrasarlo bajo ninguna circunstancia. En su ausencia, su esposa quedaría como gobernadora ${ }^{26}$. El 8 de abril informaba Martín de Salinas al archiduque Fernando de la resolución imperial de abandonar Sevilla el 25 de ese mes para ir a Granada ${ }^{27}$. Los planes previstos no se cumplirían tal como habían sido formulados, y de ello una gran culpa correspondió a Francisco I,

23 Carriazo y Antroquí, Juan de Mata (1959), p. 102: Según el marqués de Vilareal, que había acompañado a la emperatriz en su viaje desde Portugal, el emperador había mandado ajusciciar al obispo por dos razones: por el odio tan grande que le tenía, y por miedo de que pudiera despertar otra vez el recuerdo de las Comunidades.

24 GACHARD, L.P. (1874), p. 75.

29 KeNISTON, Hayward: Francisco de los Cabos. Secretario de Carlos V, Madrid 1980, p. 91: Francisco de los Cobos estuvo excomulgado durante toda su estancia en Sevilla y Granada, recibiendo la absolución en los primeros días del mes de marzo de 1527. El licenciado Ronquillo tuvo que esperar aún más como autor material de los hechos, y recibió su absolución el 8 de septiembre de 1527.

26 ARAB. Audiëntie, $n^{\circ}$ 35, p. 336: Carta de Guillermo des Batres a Margatita de Austria, Sevilla, 22 de marzo de 1526: "Madame, l'Empereur a resolu se partir de ceste ville environ la fin d'Avril pour aller en Grenade ou il ne sejournera guerres, dois la retourner a Valence et tenir les Courses d'Arragon Castellogne et Valence, puis s'en aller environ le Septembre embarquer a Barcelonne pour fair son voyage de Rome, et desja a ordonné toute son arrivée la quelle se commence a preparer. Sa Maiesté laissera l'Emperatrix par deça pour gouverner en son absence».

27 De ForondA Y AGUILERA, Manuel (1914), p. 271. 
del que comenzaban a llegar noticias sobre sus largas, tras recobrar la libertad. Al pasar la frontera, y como estaba previsto en la concordia, Francisco tenía que haber ratificado la paz ante el señor de Praet, pero se negó a ello alegando que antes tenía que procurar que los estados de su reino en París aceptaran lo firmado. Las noticias enviadas por Lannoy, que veía como su gran obra se derrumbaba, llegaron a Sevilla a principios de abril. Carlos V ordenó que Leonor no pasata a Francia ${ }^{28}$, hasta que los negocios estuvieran más claros.

En Sevilla, en su Alcázar, permaneció la pareja imperial hasta el día 14 de mayo en que partió para Granada. En una carta al duque de Borbón, escrita el mismo día de la partida, le decía: «me voy a Granada a buscar el fresco» 29 ; huía con su mujer y su corte de los primeros calores estivales sevillanos hacia la primavera granadina. Su estancia en Granada no iba a ser muy larga, ya que el emperador había planeado salir de Granada lo más tardar el día de San Juan ${ }^{30}$, para continuar su peregrinar a Roma, por lo que las noticias de sus cronistas de que Carlos iba a pasar el verano en Granada eran falsas y partían del principio de hacer la historia conociendo los resultados.

En Córdoba, donde descansó desde el 19 al 23 de mayo, recibió la noticia de la firma de la Liga de Cognac o Clementina, que creaba un ejército «defensivo" de treinta mil infantes y tres mil caballos, apoyados por artillería y una gran flota. Sus creadores, para darle realmente un carácter pacífico a esa Liga, invitaban oficialmente a entrar en ella al emperador, a condición de que hiciera una paz justa con Francia, devolviera a los rehenes y restituyera en su cargo al duque de Milán. Francisco I llegaba a ofrecer hasta tres millones de escudos de oro por la renuncia del emperador a Borgoña y la liberación de sus hijos ${ }^{31}$. El papa por su parte ya había exonerado a Francisco del cumplimiento de la paz. de Madrid por haber sido hecha sin libertad. Para facilitar el entendimiento con Carlos, la Liga le ofrecía permitirle y asegurarle el paso a Italia a coronarse, acompañado de un reducidísimo número de soldados, si aceptaba sus condiciones y entraba en ella. Si por el contrario se obstinaba y se negaba, se le haría la guerra hasta expulsarlo de Italia. Acerca de los detalles y condiciones da la Liga se enteró el emperador en su camino desde Córdoba a Granada por cartas que

28 La experiencia negativa en matrimonios anulados había marcado sin duda al césar. Él se había criado junto a su tía Margarita, que había vivido en sus carnes la afrenta de, después de pasar largo tiempo en su niñez en la corte francesa prometida al delfin, verse obligada a regresar a los Países Bajos sin boda, ya que el prometido, Carlos VII, se casaba con Ana de Bretaña, prometida a su vez de Maximiliano, el padre de Margarita. Esta doble afrenra a padre e hija, es decir tía y abuelo del empesador, así como las sufridas por él personalmente, hicieron a Carlos ser algo temeroso en cuesciones matrimoniales, en especial en las referidas a Francia.

29 AraB. Audiëntie, $n^{0} 79$, p. 2: Carta de Carlos V al duque de Borbón, Sevilla, 14 de mayo de 1526.

30 BRANDi, Karl: Carlos V. Vida y fortuna de una personalidad y de un imperio mundial, México 1993 , p. 188.

31 Galiego Morell, Antonio: «La corte de Carlos V en la Alhambra en 1526» en Misselanea de estudios dedicados al profesor Antonio Martn Ocete(Granada 1974), pp. 267-294/280. 
le envió urgentemente el embajador, Luis de Flandes, señor de Praet. A través de Castro del Río, Alcaudete y Alcalá la Real, entró Carlos el día 29 de mayo de 1526 en el reino de Granada, dirigiéndose a la ciudad de Santa Fe. En esta ciudad-campamento recibió al embajador francés Comacro, que trá́a consigo capítulos nuevos para un acuerdo, muy diferentes a los establecidos en la Concordia de Madrid. Esta vez, al menos, era el francés definitivamente claro: Francia que se negaba en rotundo a devolver el ducado de Borgoña, sí estaba dispuesta a realizar un alto pago económico por él. El emperador nada quiso saber de ello; le ordenó que informara a su dueño de su obligación como caballero de cumplir con la palabra dada, $y$ en caso de no poder hacerlo, de regresar a Castilla y entregarse como prisionero.

Tras la entrevista con Comacro la pesadumbre del emperador aumentó; sus planes para la coronación comenzaban a hacer agua el día mismo de su entrada en Granada, ciudad que por cierto le deparó un extraordinario recibimiento ese 4 de junio de 1526. Después de jurar los privilegios, usos y costumbres de la ciudad en la puerta de Elvira, escoltado bajo palio por los caballeros veinticuatro, se dirigió a la catedral, donde asistió junto a los canónigos y dignidades catedralicias a una misa de acción de gracias, retirándose a continuación a la Alhambra, su residencia en Granada.

Los primeros días pasados en Granada fueron bastante difíciles, el emperador se vio obligado a reconocer que el triunfo en Pavía y el restablecimiento de la paz entre los cristianos habían sido sólo un espejismo deseado fervientemente. La realidad a su llegada a Granada era la cruda verificación de un engaño y la posibilidad cada vez más real de un nuevo conflicto armado entre cristianos. Tres días después de su entrada en la ciudad, Martín de Salinas, embajador del infante Fernando, escribía a su señor informándole del fracaso de su petición de fondos monetarios para ayudar a Luis de Hungría en su lucha contra los turcos. El emperador, claramente contrariado por lo acontecido con el embajador francés sólo le había respondido «que harto turco tenía él entre las manos del rey de Francia» ${ }^{32}$. La confirmación de la ruptura del pacto aniquilaba las últimas esperanzas albergadas por Fernando de acceder en un período corto de tiempo al tan deseado título de rey de Romanos, pieza clave en su propio proceso dinástico.

Cada día que pasaba se veía más claro que el emperador no podría cumplir con su plan fijado de partir de Granada el día de San Juan para ir a Roma a su coronación. La comitiva teal, a falta de destino, se quedó en Granada durante seis meses y una semana esperando que la situación política italiana mejorara, que el emperador pudiera reemprender su ansiado viaje a Roma. En principio no se hablaba, ni se pensaba, suspender definitivamente el viaje imperial; oficialmente sólo sufría un aplazamiento provisional, pero sin fecha fija, hasta que

32 GaLLEGo MORELL, Antonio (1974), Ídem, pp. 267-294/280. 
no encontraran solución otros problemas que en ese momento eran más importantes para el emperador ${ }^{33}$.

Tras la negativa del emperador a modificar ni un sólo punto de la concordia de Madrid ${ }^{34}$, tal como le había confirmado a Francisco I en carta escrita de su propia mano desde Granada, el 7 de junio ${ }^{35}$, el rey francés cambió de embajador en Granada, enviando al maestre Juan de Cabilmonte, presidente de Burdeos, que llegó a la corte granadina el 20 de junio de 1526. Cabilmonte era considerado como un hombre astuto, y su misión era dar esperanzas al emperador y entretenerlo mientras se aceleraban los preparativos militares. En su primera entrevista oficial con el emperador, en la Alhambra, el 22 de junio, se hizo acompañar por los embajadores de todos los príncipes italianos comprometidos en la Liga de Cognac, entre los que destacaban Baltasar Castiglione, en nombre del papa, y Andrés Navagero, representando a Venecia, pero también por Eduardo Leo, representante de Enrique VIII. En nombre de todos ellos, Castiglione, gran orador, solicitó la devolución de los hijos de Francisco mediante un honesto rescate, el perdón para Francisco Sforza, y su consecuente restitución del ducado de Milán, y el abandono de la Lombardía y Nápoles por las fuerzas españolas, ofertando al emperador generosamente el plazo de un mes para que se decidiera antes de comenzar las hostilidades.

Las hostilidades llegaron, primero como pequeñas escaramuzas en torno a Milán, para luego pasar a convertirse en un conflicto generalizado en todos los frentes. El emperador era obligado por el destino a disfrutar, mientras las múltiples actividades políticas se lo permitieran, de una prolongada luna de miel en Granada. Durante medio año, esta ciudad se convirtió en residencia de la corte imperial y en centro de la política mundial, el mundo redescubría nuevamente esta ciudad semiolvidada desde su reconquista. Tanto para el emperador como para Granada, la estadía imperial de 1526 supondría unos meses inolvidables. El emperador, aunque acosado por los muchos problemas políticos, disfrutó en Granada de un largo período de tiempo cerca de su amada mujer; disfrutó con sus más íntimos amigos de su actividad favorita, la caza. Los bosques de las montañas cercanas a la vega granadina, y en especial el Soto de Roma, no lejos de Santa Fe, fueron los lugares preferidos de Carlos para su ac-

33 BRANDI, Karl (1993), p. 188.

34 De Fononda y Aguilera, Manuel (1914), p. 266: Carlos V nunca pensó que se hubiera aprovechado del cautiverio de Prancisco I para imponerle los puntos de la Concordia de Madrid, muy al contrario él consideraba que se había comportado como un caballero y no se había aprovechado de la situación política. En carta escrita desde Toledo el 26 de enero de 1526, a Agustín Grimaldi, obispo de Grasa y señor de Mónaco, Carlos le decía que después de la batalla de Pavía hubiera podido invadir Francia sin problemas, pero que había preferido la paz, bajo la base de la restitución de Borgoña y de los derechos sobre Nápoles y el Milanesado, a la guerra.

35 TYLLER, Royall (1972), p. 161: Reproduce fotográficamente la carta completa, y aunque con dificultades, puede ser leída en su integridad. La carta está escrita por el emperador de su propia mano.

Hispaniq, LX/3, núm. 206 (2000) 835-852 
tividad cinegética, en la que como siempre, por su carácter atrevido, se vio en más de una ocasión en grave peligro. Junto a ello, el césar descubrió un mundo exótico, el de los moriscos granadinos, admiró y disfrutó de sus bailes y en especial, como gran melómano, de su música. Los banquetes, recepciones, saraos, frestas privadas y públicas organizadas por la ciudad en su honor, llenas de exotismo y en el marco incomparable de la Alhambra, dejaron huella en el emperador. Al mismo tiempo, Granada recibía un sinfín de fundaciones: la continuación de las obras del Hospital Real, un nuevo hospital para niños expuestos, una nueva casa de locos, el Colegio de San Miguel, el Colegio Imperial de la Santa Cruz, el Colegio Eclesiástico, la Universidad católica, el Palacio de Carlos V, la Puerta de las Granadas, el Pilar Imperial, la continuación de las obras de la Catedral como panteón de la dinastía, las mejoras llevadas a cabo en la Capilla Real, Alhambra y Generalife, la iglesia de San Matías, y otras obras, que mantuvieron viva la estancia del emperador hasta finales del siglo XVI. Además la presencia imperial tuvo fuertes repercusiones en casi todas las instituciones granadinas, en el Ayuntamiento, en la Real Chancillería y Audiencia, en las instituciones dependientes del arzobispado de Granada. Algunos de sus consejos de gobierno, como el de Estado, sufrieron profundas transformaciones; otros, como el de Indias, fueron pródigos en nuevas legislaciones defendiendo a los indígenas americanos de la depredación de los conquistadores. Se creó la Santa Hermandad para defender los caminos y campos del reino, y desgraciadamente se trasladó el tribunal de la inquisición de Jaén a Granada. Pero uno de los temas en los que la estancia imperial en Granada tuvo más influencia fue el de los moriscos, revisándose su "conversión» y la persecución y abusos a que eran sometidos por los nuevos repobladores del reino, cristianos viejos. La reunión de la «Catholica Congregación» del 7 de diciembre de 1526, en la Capilla Real, estableció las bases del nuevo sistema de convivencia entre cristianos nuevos y viejos en el reino de Granada, que se mantendría hasta su final levantamiento y expulsión.

Para Carlos, como vemos, el tiempo pasado en su mayor ciudad peninsular no fue baldío. Su actividad fue extraordinaria en el ámbito político, en los cientos de cartas dictadas o recibidas de toda Europa, con especial incidencia de Italia, lugar básico del conflicto armado. Ayudado por sus secretarios Jehan Lallemand, Francisco de los Cobos y Alfonso de Valdés ${ }^{36}$ dirigió, por medio de epístolas en los más diversos idiomas, la política y la actividad militar de los suyos. Granada brillaba en la figura de su emperador, de su corte cosmopolita, de sus invitados y embajadores.

\footnotetext{
36 El conde Mercurino Gattinara estuyo ausente hasta bien entrado el otoño. En Sevilla, debido a una serie de conflictos administrativos, había recibido permiso del emperador para ausentarse de la corte durante un tiempo. Alejado de la actividad política durante la primavera y el verano de 1526 , regresó a Granada en el otoño intentando retomar las riendas de un gobierno, que ya nunca más controlaría como el deseaba. Cobos comenzaba su imparable ascenso personal.
} 
Para nosotros en este pequeño trabajo sobre el proceso dinástico del emperador, el momento culminante de la estancia imperial en Granada fue el del embarazo de Isabel de Portugal. Creemos que ya desde principios de julio, tras los grandes terremotos del día 5 de ese mes, Isabel que había residido hasta ese momento en los aposentos situados sobre el Cuarto Dorado de la Alhambra, trasladó su residencia a un lugar más seguro, el monasterio de la orden jerónima en la Vega, cerca de las murallas de Granada. Las visitas y estancias prolongadas del emperador en el monasterio se hicieron normales. Fruto del inmenso amor que se demostraban fue el embarazo de la emperatriz, calculado por el cronista granadino Bermúdez de Pedraza en el día 21 de agosto de 1526 , y que fue anunciado a bombo y platillo el 15 de septiembre de ese año. Era ésta una razón más para prolongar la estadía en Granada, buscando tranquilidad para Isabel y asegurando ese embarazo tan deseado en todos los reinos del emperador. Granada se mostraba orgullosa de ello, contenta de haber sido el lugar donde fuera engendrado el futuro hijo/a, que Dios mediante podría ser incluso el heredero de tan vastas posesiones. Sevilla, que disputaba con Granada por ser el lugar de la procreación, no cesaría en su empeño hasta que el paso del tiempo diera la razón a Granada. El destino había querido asegurar la sucesión dinástica en los territorios hereditarios antes que atar los cabos en el Imperio. Fernando tenía ahora que esperar a que la situación político-militar cambiara para poder conseguir su ansiado objetivo, y eso a pesar de la actividad constante de su embajador Martín de Salinas que no permitía enfriarse la idea del viaje a Roma en el emperador. A lo largo del mes de julio a punto estuvo de conseguirlo y la idea de la coronación imperial volvió a surgir con toda su fuerza en la corte alhambreña. El emperador escribió en ese sentido al condestable de Borbón, aunque al final todo quedara en un intento o en una ilusión irrealizable por el momento ${ }^{37}$.

La llegada de la noticia de la muerte de Luis I de Hungría a la corte granadina, el 13 de noviembre de $1526^{38}$, supuso el fin de la luna de miel imperial y el comienzo de los preparativos para abandonar la ciudad. Las tierras familiares y hereditarias de los Habsburgo estaban ahora en peligro y a merced del turco, del que se pensaba que no atacaría durante el invierno, pero del que se temía un ataque masivo llegada la primavera. La idea de la coronación quedaba definitivamente pospuesta, así como el empeño de recobrar el ducado de Borgoña. El 5 de diciembre, Carlos convocó urgentemente cortes generales en Valladolid para el 20 de enero de 1527, intentando recabar ayuda económica para financiar al ejército beligerante y para apoyar a su hermano.

37 ARAB, Audiëntie, $n^{\circ} 79$, p. 8: Carta de Carlos V al condestable de Borbón, Granada, 6 de julio de 1526.

${ }_{38}$ ARAB. Audièntie, n ${ }^{\circ} 43$ : La noticia le llegó al emperador ese día por medio de una carta del archiduque Fernando, rey electo de Bohemia, escrita en Linz el 22 de septiembre de 1526.

Hispania, LX/3, núm. 206 (2000) 835-852 
Carlos despachó también desde Granada cartas a los príncipes alemanes, justificando la guerra contra la Liga, pidiéndoles ayuda para defender al Imperio del avance turco y conminándolos a tomar las armas para esa defensa. Escribió cartas con el mismo fin a los reyes de Dinamarca y Polonia, y a algunos príncipes italianos, e incluso tendió un primer puente de plata a Francisco I, al que estaba dispuesto a perdonar todas las injurias, si mudase de propósito.

Después de las agotadoras jornadas vividas en los últimos días de estancia en Granada, en los que el número de cédulas reales, fundaciones y reuniones se multiplicaron, intentando poner en orden todo lo iniciado en la ciudad antes de partir, salió el emperador de Granada pasado el mediodía del 10 de diciembre de 1526. El invierno ese año fue durísimo y la travesía hasta Castilla fue una verdadera epopeya para la comitiva imperial, con abundantes nieves, ríos desbordados y caminos intransitables. El emperador se despertaba tarde y tras almorzar continuaba la marcha hasta la hora de cenar. En Toledo pasó la Navidad y luego fue a Tordesillas, quedando con su madre quince días, e hizo su entrada en Valladolid el 8 de febrero de $1526^{39}$. Las cortes generales comenzaron el 11 de febrero.

Debido al estado de la emperatriz y al mal tiempo reinante, Isabel permaneció en Granada a pesar de la partida del emperador. Así nos lo describe Alonso de Santa Cruz, que cuenta que la emperatriz se quedó en Granada hasta finales de diciembre, y pasadas las Pascuas, partió para Jaén, desde donde continuó a Toledo, para unirse con su marido en Valladolid ${ }^{\top 0}$. En carta escrita en Valladolid el 16 de febrero de 1527, Martín de Salinas informaba al rey de Bohemia, Fernando, de que ese día el emperador había salido de Valladolid hacia Segovia, para recibir a la emperatriz que iba a hacer su entrada en esa ciudad. Desde Segovia, acompañada por el emperador llegó a Valladolid el 22 de febrero ${ }^{41}$.

De nuevo el destino fue vital en el proceso dinástico, en este caso para Fernando. La muerte del rey Luis en Mohacs, le permitió, por medio de una política inteligente, ser elegido el 22 de octubre de 1526 por la dieta de los estados de Bohemia como sucesor de su cuñado. Tanto su hermana María, reina viuda, como su hermano Carlos accedieron rápidamente a cederle todos los derechos que pudieran tener sobre Bohemia y Hungría, así como a enviarle con presteza la investidura, ya que el reino de Bohemia era parte del Imperio y sin la investidura imperial el nombramiento carecía de valor ${ }^{42}$. Quizás como homenaje a

39 GACHARD, P.L. (1874), p. 77.

40 De SANTA CRuZ, Alonso (1920), p. 280: «La emperatriz quedó en Granada todo el mes de diciembre y pasadas las Pascuas se parció para Jaén".

(1) De Foronda Y AGUilera, Manuel (1914), p. 286.

42 LANZ, Karl (1966), p. 226. Carta de Carlos a Fernando, Granada, 30 de noviembre de 1526: «Car encoires qui fust besoing de vous ayder de chose que en ce me pourroit appartenir, je vous advertiz que, si purement et plainement les dicts royaulmes (Bohemia y Hungría) estoient a moy, je vous en feoye tres voluntiers le don, et des maintenant, si quelque chose je y puis ou pou-

Huspania, LX/3, núm. 206 (2000) 835-852 
su hermano, Fernando se hizo coronar rey de Bohemia el día 24 de febrero de 1527, cumpleaños del emperador. De igual forma, aunque con muchos más dificultades por existir un opositor, accedió Fernando también a la corona electiva de Hungría. Pero no terminaban ahí las aspiraciones dinásticas de Fernando, que pretendió también ser nombrado por su hermano duque de Milán, a lo que Carlos se negó en redondo. Fernando sabía como presionar a Carlos, y de hecho se conservan varios documentos en los que intenta obtener sus objetivos haciéndolo sentirse culpable de que el hubiera tenido que abandonar su tierra donde babia nacido y criádome ... negando el amor de la patria por el de su servicio, a veces también le recordaba su matrimonio con Ana de Hungría, conforme a su mandato, sin haberla conocido antes ${ }^{43}$.

Carlos $\mathrm{V}$ también estaba llegando a la cumbre de su proceso dinástico con el cercano nacimiento de su heredero, y parecía pretender acabar con el conflicto armado antes de que ocurriera. En marzo de 1527, su visión de la disputa mutua y sus pretensiones con respecto a Francisco I habían cambiado radicalmente y parecía buscar un camino hacia la paz, aunque debido a lo que ambos monarcas se habían dicho y exigido la solución no parecía ser fácil ${ }^{44}$. Fernando perseguía también esa paz para poder proteger sus nuevas adquisiciones, y por ello estaba dispuesto a liegar aún más lejos que Carlos, lo que no parecía agradar al emperador ${ }^{45}$.

La paz no fue posible, al menos en ese momento, el conflicto continuó en todos los frentes. En medio de él y «passando harto trabajo» alumbraba Isabel en Valladolid, el 21 de mayo de 1527, un varón, el deseado heredero, que sería bautizado el 5 de junio con el nombre de Felipe $e^{46}$. La noticia se expandío por todos los reinos, llegando hasta los más humildes ámbitos rurales con la gran alegría de todos. Sin embargo ese feliz acontecimiento se vio rápidamente em-

rroye pretendre pour la sucession de feu nostre grand pere que dieu absoille, je le vous donne de tres bon cueur; car je sceay bien, que en ce monde ne le savroye autrepart mieulx ne si bien employer que a vous que j'ayme et extime comme ung autre moymesmes. Er quanr au dict royaulme de Boheme ... je vous envoye l'investiture que demandez, mais pour ce que aucuns veullent dire, que le dict royaulme est exempt de l'empire ....

43 Fernández Álvarez, Manuel (1973), p. 161, 59.

44 LANZ, Karl (1966), p. 229. Instrucciones de Carlos al barón de Montfort, Valladolid, 16 de marzo de 1527: «Vous lui remontrerez et direz, que s'il ne porte autre chose, et que le roi de France ne veuille accomplir ce de Madrid, la difficulte qu'il y auroit de pouvoir m'accorder avec lui; car s'il ne l'accomplit, je ne sais, commment je pourrois me dedire de ce que j'ai dit de lui, ou souffrir qu'il ne se dedie de ce qu'il m'avoit dementi; et que sont deux choses fortes a fairem.

45 LANZ, Karl (1966), p. 229. Instrucciones de Carlos al barón de Montfort: aJ'ai reçu lettre du toi mon frere (Fernando), ou il me sollicite de la paix le plus fort du monde, et comme si je n'en avois nulle volonte, et meme me semble qu'il desire de la traiter ... je la desire, mais non point pour etre trompe et apres inculpe d'avoir fait faute ... le pourriez assurer, que plustot faire paix non honorable et sans assurance, que aimerez mieux y mettre le tout a l'avanture».

46 Fernández Álvarez, Manuel (1973), p. 123: Carta de Carlos V a Lope de Soria, Valladolid, 22 de mayo de 1527. 
pañado por el trágico suceso del Saco de Roma, que obligó al emperador a suspender las fiestas planeadas para su celebración.

La guerra continuó indecisa hasta la derrota del ejército francés comandado por Lautrec en Nápoles. En el otoño de 1528, Carlos se decidió a pasar a la acción y acabar militarmente con el conflicto bélico. Para ello pretendía abrit tres frentes a Francisco I, y atacarle desde Flandes, desde el Imperio y desde Italia hacia el corazón de Francia. Los preparativos para el traslado del emperador se pusieton en marcha, ya que su estrategia militar exigía su paso personal a Italia, y su puesta al frente del ejército. No le dio tiempo a ello, ya que Francisco I se decidió finalmente por la paz, firmada en Cambray en julio de 1529. En esta paz, en la que entre otras cosas los duques de Borgoña dejaban de ser vasallos del rey francés por sus tierras de Artois y Flandes, en la que Tournais era integrada definitivamente en el Círculo Imperial de Borgoña, Francisco I se comprometía a pagar dos millones de coronas por la liberación de sus hijos, y a contribuir con veinte galeras y doscientos mil taleros como ayuda al viaje del emperador para su coronación en Italia. De la firma de la paz se enteró Carlos en plena travesía hacia Italia, recibiendo confirmación de ello a su llegada a Génova el 12 de agosto de 1529. Había dejado, como desde un principio lo tenía planeado a su mujer Isabel de regente en la península, ayudada por un equipo de consejeros.

El 24 de feberero de 1530, el día de su cumpleaños, recibía Carlos de manos del papa en Bolonia la unción y la deseada corona imperial, y con ello quedaba expedito el camino para la elección de Fernando como rey de Romanos, ocurrida en 1531, y su posible sucesión en el Imperio.

Carlos poseía ya su heredero, Felipe, jurado como tal por las cortes de Castilla y de Aragón. No obstante, la presión sobre la pareja imperial para asegurar la herencia no cesaba. En julio de 1528 alumbraba Isabel una hija, María, en 1529, un hijo Fernando, que Carlos no llegó a conocer por haber muerto antes de su regreso a España. En la felicitación de Margarita de Austria, gobernadora de los Países Bajos, a Isabel de Portugal tras el nacimiento del infante Fernando se seguía presionando para que tuviera aún más hijos que aseguraran la herencia: «... yo solicitaré a su magestad, quando le viere, que os vaya a ver para que comiençe otro, que gracias a Dios, él no ha menester otra cosa sino hijos para poseer los grandes reynos y tierras que Dios le ha dado ${ }^{47}$. Dos hijos más tuvo la pareja imperial, un varón, Juan, muerto muy joven, y una hija, Juana.

47 Fernández Álvakez, Manuel (1973), p. 186: Carta de Margarita de Austria a la emperatriz Isabel, Bruselas, 15 de diciembre de 1529 .

Hispania, LX/3, núm. 206 (2000) 835-852 